\title{
Mining and Analyzing Circulation and ILL Data for Informed Collection Development
}

\section{Forrest E. Link, Yuji Tosaka, and Cathy Weng}

The authors investigated quantitative methods of collection use analysis employing library data that are available in ILS and ILL systems to better understand library collection use and user needs. For the purpose of the study, the authors extracted circulation and ILL records from the library's systems using data-mining techniques. By comparing these data to records of books acquired in a four-year period, the study reveals generally good collection use as well as some unmet collection needs. The study also offers a method of compiling and sharing these multiple types of usage data among work groups to create feedback mechanisms to inform the work of selectors and suggest modifications to collection development practices.

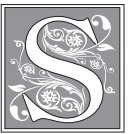

tudying library collection use is an essential part of understanding what user communities need and evaluating how well the collection is meeting those needs. Academic libraries often have undertaken this assessment on a prospective basis by employing subject specialist librarians (either in-house or by proxy through approval plans). These selectors have familiarized themselves with their users' research areas to identify and select what they consider to be the most appropriate materials accordingly. It has not, however, always been clear to what extent such selector-based practices actually satisfy user needs. Coming from a wide range of scholarly and learning interests, some studies have emphasized the importance of use-centered, evidence-based collection evaluation. ${ }^{1}$ Indeed, as Bodi and MaierO'Shea suggested, such approaches are even more strategically important to smaller academic libraries that have to develop more selective collections using usage-based approaches because of tight budgets and finite resources. ${ }^{2}$ Thus, examining evidence of library usage patterns can offer insights into how well-or how poorly-a library's collection is meeting its users' needs and help ensure a return on the investment from the existing resources spent on collection development.

The purpose of this paper is to report a study that the authors at The College of New Jersey Library undertook to develop a simple, practical method for evaluating collections in terms of usage patterns. As various library systems now have increasingly sophisticated data-mining capabilities, a wealth of management data surrounding purchasing records, circulation transactions, and interlibrary loan (ILL) requests has

Forrest E. Link is Acquisitions Librarian, Yuji Tosaka is Cataloging/Metadata Librarian, and Cathy Weng is Head of Cataloging at The College of New Jersey; e-mail: linkf@tcnj.edu, tosaka@tcnj.edu,weng@tcnj. edu. (C2015 Forrest E. Link, Yuji Tosaka, and Cathy Weng, Attribution-NonCommercial (http://creativecommons.org/licenses/by-nc/3.0/) CC BY-NC. 
accumulated that has often remained untapped and unrealized for meaningful analytics. By compiling and analyzing these data, we aimed to find better ways to measure our user needs, assess the results of our collection practices, and identify how our users have interacted with library collections. By conducting similar evidence-based evaluation of library use patterns, we believe that academic libraries should be able to create effective feedback mechanisms to monitor and inform their collection development practices to better meet the changing needs of their user populations.

\section{Literature Review}

Employing library usage data to assess and inform collection development has been discussed in several different ways in the library literature. Analyzing circulation data-representing how materials owned by libraries have been used - to measure collection performance is the most direct way to learn collection use. Jain proposed a classic concept of "relative use" - measured as the percentage of circulation and in-house use against holdings - as a sampling and data collection method for a bookuse study. ${ }^{3}$ Bonn introduced the notion of "use factor" - the ratio of circulation to holdings-as a key method for evaluating library collections and detecting overselection (materials acquired, but not used) and underselection (materials wanted, but not acquired). ${ }^{4}$ Some studies since then have examined circulation statistics of titles acquired by different selection groups (such as librarians vs. faculty or librarians' vs. vendors' approval plans) to evaluate the effectiveness of selection practices. Dinkins collected and compared circulation statistics of titles selected over a five-year period by departmental faculty and librarians to learn if usage of the materials selected by faculty outperformed that of titles selected by librarians. ${ }^{5}$ Brush studied circulation data of engineering titles ordered through an approval plan and compared them to the total circulation data of titles in the whole engineering collection (Library of Congress Classification T class) over the same period. ${ }^{6}$ The purpose of the study was to assess the value of using approval plans in her library. Adams and Noel studied circulation statistics for collection evaluation purposes by comparing the usage of titles by subject, publisher, and publication date. ${ }^{7}$ Kohn exercised a different approach measuring her library's collection use. Using call number ranges, her study focused on total and unique circulation data for different parts of her library's holdings that served specific undergraduate courses. ${ }^{8}$

While circulation statistics represent how materials owned by libraries have been used, usage data could also include ILL data, which represent materials not owned but in demand. Analysis of such usage data can be incorporated to help inform collection development practices. No single library can satisfy all local user needs; therefore, use of other library collections may become even more important in a networked, resourcesharing environment today. Byrd et al. proposed a statistical method for determining subject strengths and weaknesses in library collection in relation to user demand by using new acquisitions and ILL data. ${ }^{9}$ The authors developed a formula to calculate relative percentage of collection balance indicators. If the proportion of ILL requests in specific subjects was higher than that of new acquisitions in the same subject areas, then a negative collection balance was detected. They concluded that, by using such a mechanism regularly, a library could "measure the impact of previous collection development efforts" and "help predict future user needs." 10

The aforementioned studies used either only circulation data to measure library collection use or ILL data to measure the collection balance or the quality of ILL titles. A few other studies have used a combination of circulation and ILL data to get a broader picture of user needs to inform collection development. Anguilar introduced a method for analyzing library holdings, circulation, and ILL data to study library collection 
use. ${ }^{11}$ His article described a method of evaluating collection use by applying Bonn's "use factor" for each subject. He then developed the "ratio of borrowings to holdings" (RBH) to analyze ILL borrowings data by subject. Results from the two formulas were compared to detect overused/underused subject classes. The author suggested that the ideal situation for a library was the combination of high local collection use and a low ILL rate for each subject area. Likewise, Henderson proposed the library collection failure quotient (CFQ) - the ratio of ILL borrowings to entire holdings - and contended that a high CFQ score was a sign of the failure of a library collection to meet user needs. Ochola used the method described in Anguilar's article and examined both circulation and ILL data to identify underused collections for possible off-site storage and for collection development purposes. ${ }^{12}$ His findings identified the subject areas of titles that the library owned and were heavily used along with those of titles that were not owned but in high demand. Knievel et al. later conducted research using a combination of the entire library holdings, circulation transactions, and ILL data to inform collection management. Specifically, the authors compared a set of data with overall library holdings of targeted collections, average transactions per item, percentage of items circulated in specific subject areas, and ratio of ILL data to library holdings by subject. ${ }^{13}$

As shown above, past studies on usage-based evaluation of collection development have left a number of important questions unanswered. Despite their unique contributions to the literature, studies that have established basic research methods in the field-such as "relative use" (Jain), "use factor" (Bonn), "RBH" (Aguilar), and "CFQ" (Henderson)- have examined the relationships of circulation, in-house use, and/or ILL borrowings data to the entire holdings data only. One major drawback of these methods is that they fail to look at these data sets more granularly by accounting for variances across subjects or currency of materials acquired or used. None of these studies accounts for the possibility that library collections may be more dynamic and evolving constantly, with different subject librarians or vendors handling collection development tasks over the years. A mechanism is clearly needed to monitor the effectiveness of current collection development practices, which follows how recently collected materials are being used. Further, previous studies also fail to address how circulation and ILL data can help monitor current user needs, which may be rapidly changing. Also, few previous studies have effectively incorporated acquisitions data-a key measure of collection development activities - in combination with various types of usage data for informing better selection strategies. Additionally, while some studies have interpreted too many ILL requests as an indicator of "library collection failure" (Henderson), relationships among recent acquisitions, circulation, and ILL borrowings data need to be examined more carefully to determine subject strengths and weaknesses in relation to the total user demand for library materials. Moreover, because academic libraries serve different user populations (for example: undergraduates, graduate students, faculty), it is also essential that efforts be made to disaggregate all these data sets and analyze them on a smaller scale to examine the effectiveness of collection development activities for different user categories.

\section{The Study Environment, Data, and Methods}

Situated in Ewing, New Jersey, The College of New Jersey (TCNJ) is a four-year institution with approximately 6,300 full-time undergraduate and 200 full-time graduate students and 350 full-time faculty members. ${ }^{14}$ The College offers a variety of degree programs through its seven schools with limited graduate programs in the School of Education and the School of Nursing, Health \& Exercise Science. The College of New Jersey Library has a mid-sized library holding over 600,000 print volumes and other materials in various formats. 
The current study sought to investigate new ways to provide a simple yet pragmatic and effective method for pulling together multiple types of usage data to evaluate user needs and develop strategies for better collection building. Using acquisitions and circulation data available from our Voyager integrated library system, the authors analyzed recent print monographs purchased to see how well (or poorly) those new acquisitions had circulated. The study also examined recent borrowing activity via ILL using the local ILL data from the OCLC WorldCat Resource Sharing system. These data sets were analyzed by subject using LC classes in an effort to discover whether and how well library monograph purchases had been used. In so doing, the study has led us to consider how usage data could help define and answer the fundamental questions of collection development: Are we collecting what our users need? Can usage data help us pinpoint these needs? Have we sufficiently served both our faculty and students? Do ILL requests represent collection failures or user wants beyond the scope of current collection policies? By helping to provide fresh insights into these questions, the ultimate goal of this study was to refresh the dialogue between selectors and users and to re-energize library collection development thinking.

Three basic initial assumptions underlaid our current study:

1. Effective collection development can be measured by the extent to which our collection is used.

2. Any circulation of titles means that user needs are being met.

3. User needs can be represented by the circulation of titles owned and by the provision of titles not owned but borrowed through ILL.

As described above, the authors used three data sets for the purpose of the current study: 1) recent acquisitions data, 2) circulation data for recent acquisitions, and 3) ILL borrowings data of recent imprints. For recent acquisitions data, we turned to the local Voyager system to extract the records of new acquisitions of print monographs ordered and cataloged for our circulating General Collections for the four fiscal-year period from July 2008 to June 2012. This four-year period was chosen in large part because no comparable ILL data were available prior to that time. We found that a large percentage (more than 80 percent) of new acquisitions added to our collection were those with 2007 imprints or later (see table 1). Based on the imprint data for new acquisitions, we decided that we would focus on recent titles with 2007 imprints or later in analyzing circulation and ILL data for the sake of comparability.

For circulation data, the authors likewise turned to the local Voyager system to extract the circulation transaction records for the same period. The date each title was cataloged and added to our local collections was used to create a new subset of the circulation data for new acquisitions with 2007 imprints or later. In this process, date stamps for circulation were also included and later used to calculate the circulation of unique titles that were charged during the study period. In addition, each circulation transaction record extracted included patron group data predefined in the local Voyager system that allowed us to identify which type of user checked out a particular item. For the ILL data, we pulled the records of print monograph titles borrowed during the same period from the OCLC WorldCat Resource Sharing system with the same patron group data and created a subset of the ILL data for titles with 2007 imprints or later. Then, we used the codes for our three main patron groups - faculty and staff, undergraduates, and graduate students - to filter the circulation and ILL data sets and analyze how borrowing patterns varied in various subject areas across these patron groups. (Because of the academic focus of our library collection, the "faculty and staff" patron group is used in the following pages to represent borrowings by our faculty members.) For this study, we used LC classes as indicators of different subject areas. 


\begin{tabular}{|c|c|c|}
\hline \multicolumn{3}{|c|}{ TABLE 1 } \\
Number of Unique Titles Acquired for General Collection, \\
FY 2008/09-2011/12 \\
\hline Imprint Date & Number of Unique Titles & Percent \\
\hline Pre-2000 imprints & 994 & $6.2 \%$ \\
\hline $2000-2006$ & 1,967 & $12.2 \%$ \\
\hline 2007 & 1,391 & $8.6 \%$ \\
\hline 2008 & 3,290 & $20.5 \%$ \\
\hline 2009 & 3,215 & $20.0 \%$ \\
\hline 2010 & 2,618 & $16.3 \%$ \\
\hline 2011 & 1,954 & $12.1 \%$ \\
\hline 2012 & 642 & $4.0 \%$ \\
\hline 2013 & 13 & $0.1 \%$ \\
\hline$($ Total $)$ & $(16,084)$ & $(100 \%)$ \\
\hline
\end{tabular}

It is necessary to note that e-book usage and analysis are not included in this study. TCNJ Library began to purchase e-books in the spring of 2012. The e-book titles, however, were not made available to the library's online catalog for discovery until the summer of 2012, which is beyond the study period. Also collecting and analyzing e-book usage data (for example, number of downloads vs. number of checkouts, browse vs. use of e-books based on view time, and so on) may not be quite comparable to their print counterparts. In addition, because of licensing restrictions that limit the sharing of e-books among libraries, any ILL data gathered would be limited and inconsistent with data derived from print book borrowing.

\section{Results and Analysis}

Preliminary analysis of our data sets revealed that certain LC classes were represented at such low levels of acquisitions, ILL, and circulation that their inclusion in the study would be meaningless. Specifically, titles in LC classes A (General Works), C (Auxiliary Sciences of History), S (Agriculture), U (Military Science), and V (Naval Science) each represented less than 1 percent of the total data. We decided to eliminate titles in these LC classes from our study.

As shown in table 2, in the four-year period between FY 2008-2009 and FY 2011-2012, TCNJ Library purchased and added to the General Collections 16,084 monographs, of which 13,123 unique titles had an imprint date of 2007 or later. Removing titles in LC classes A, C, S, U, or V resulted in a group of 13,003 books. In the same period, 60,273 unique titles circulated, of which 5,043 had imprint dates of 2007 or later and were not in LC classes A, C, S, U, or V. (Please note that, while new acquisitions seem to represent a very small percentage of total circulation, they circulated significantly well when measured against the total number of new items acquired.) Also in this same period, the library borrowed 5,636 books via ILL. Of these, 1,483 unique titles had imprint dates of 2007 or later and were not in LC classes A, C, S, U, or V.

Examining purchases in the study period by subject (see figure 1), the authors found that books in LC classes H (Social Sciences) and P (Language and Literature) constituted the largest percentage of titles acquired, about 21 percent and 15 percent respectively. Titles in these LC classes were followed by those in LC class Q (Science) at 9 percent and LC classes B (Philosophy, Psychology, Religion) and L (Education) 


\begin{tabular}{|c|c|}
\hline \multicolumn{2}{|l|}{$\begin{array}{l}\text { TABLE } 2 \\
\text { Data Set }\end{array}$} \\
\hline \multicolumn{2}{|l|}{ Acquired Books } \\
\hline Total Unique Titles Acquired 2008-2012 & 16,084 \\
\hline 2007 and Later Imprint & 13,123 \\
\hline 2007 and Later Imprint (Minus LC classes A, C, S, U, V) & 13,003 \\
\hline \multicolumn{2}{|l|}{ Circulation } \\
\hline Total Books Circulated & 127,374 \\
\hline Unique Titles Circulated & 60,273 \\
\hline $\begin{array}{l}\text { Total Circulations of } 2007 \text { and Later Imprints Acquired (Minus LC Classes A, } \\
\text { C, S, U, V) }\end{array}$ & 10,269 \\
\hline $\begin{array}{l}\text { Circulation of Unique Titles Acquired } 2007 \text { and Later (Minus LC Classes A, C, } \\
\text { S, U, V) }\end{array}$ & 5,043 \\
\hline \multicolumn{2}{|l|}{ ILL } \\
\hline Books Borrowed & 5,636 \\
\hline 2007 and Later Imprint Minus LC Classes A, C, S, U, V & 1,682 \\
\hline Unique Titles 2007 and Later Imprint (Minus LC Classes A, C, S, U, V) & 1,483 \\
\hline
\end{tabular}

at 8 percent. These findings reflected our recent collection policies. Figure 2 presents data on the circulation of these titles, examining both total circulation and the number of unique titles circulated by subject. When the overall percentage of books acquired by subject is compared to books circulated by subject, a close parallel is noted both in total circulation and the number of unique titles circulated. The data seem to provide a good measure of the recent success in collection development at TCNJ Library, showing clearly that the library is circulating in proportion to what it is buying.

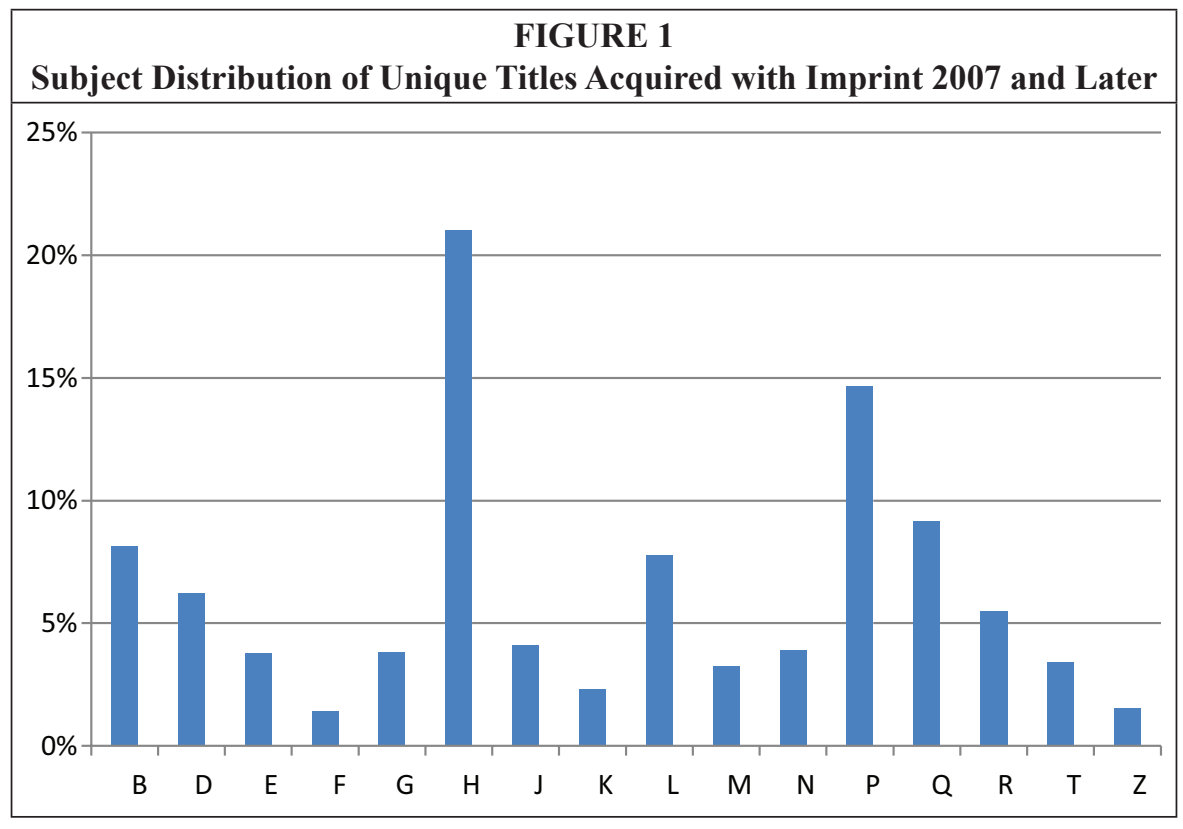




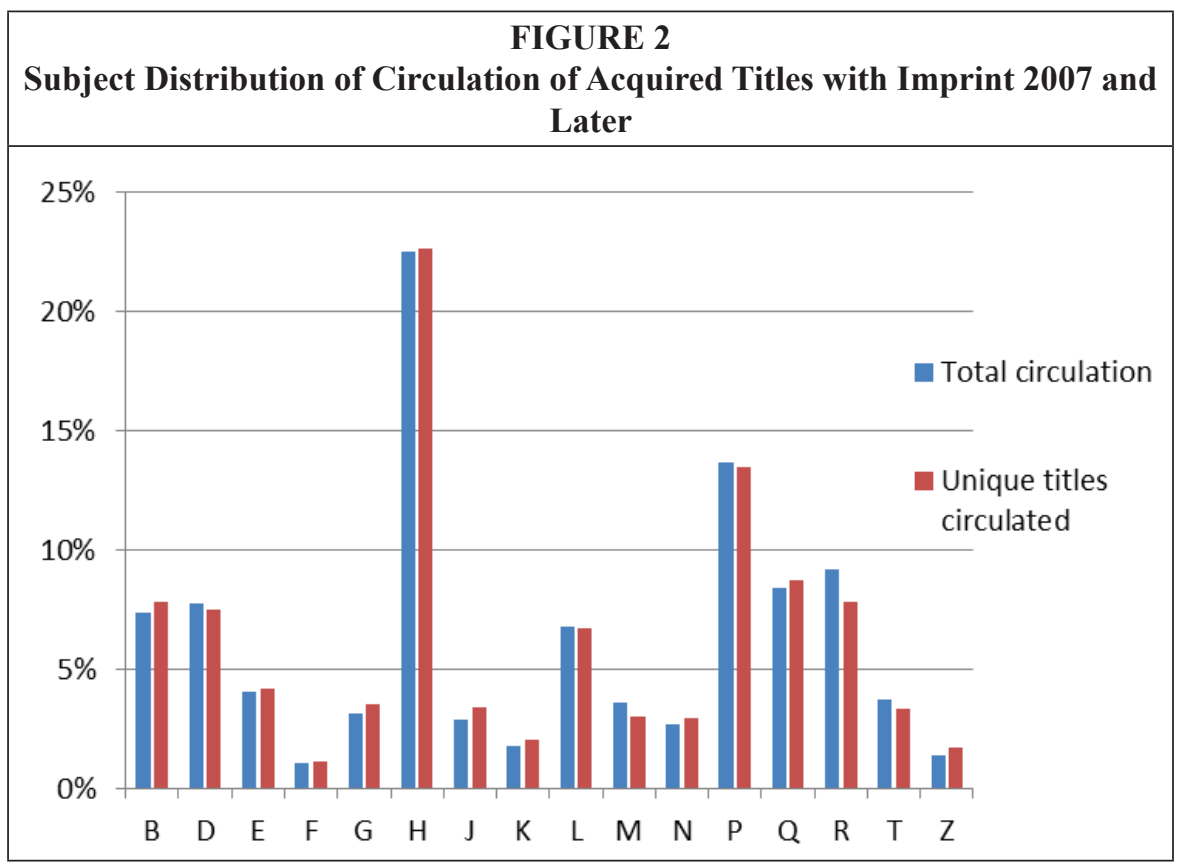

Next, figure 3 illustrates a different way of examining how well newly acquired titles circulated by LC class. Specifically, the figure represents the percentage of unique new titles within each LC class that were checked out during the study period. As shown, nearly 40 percent of titles acquired have circulated at least once. LC class R (Medicine) has recorded the highest percentage of unique title circulation, with 55 percent of newly acquired titles checked out at least once during the study period. This largely matches the results reported by Ludwig and Miller, for example, whose study found similar circulation rates for new purchases in two large research libraries. ${ }^{15}$ Since the results

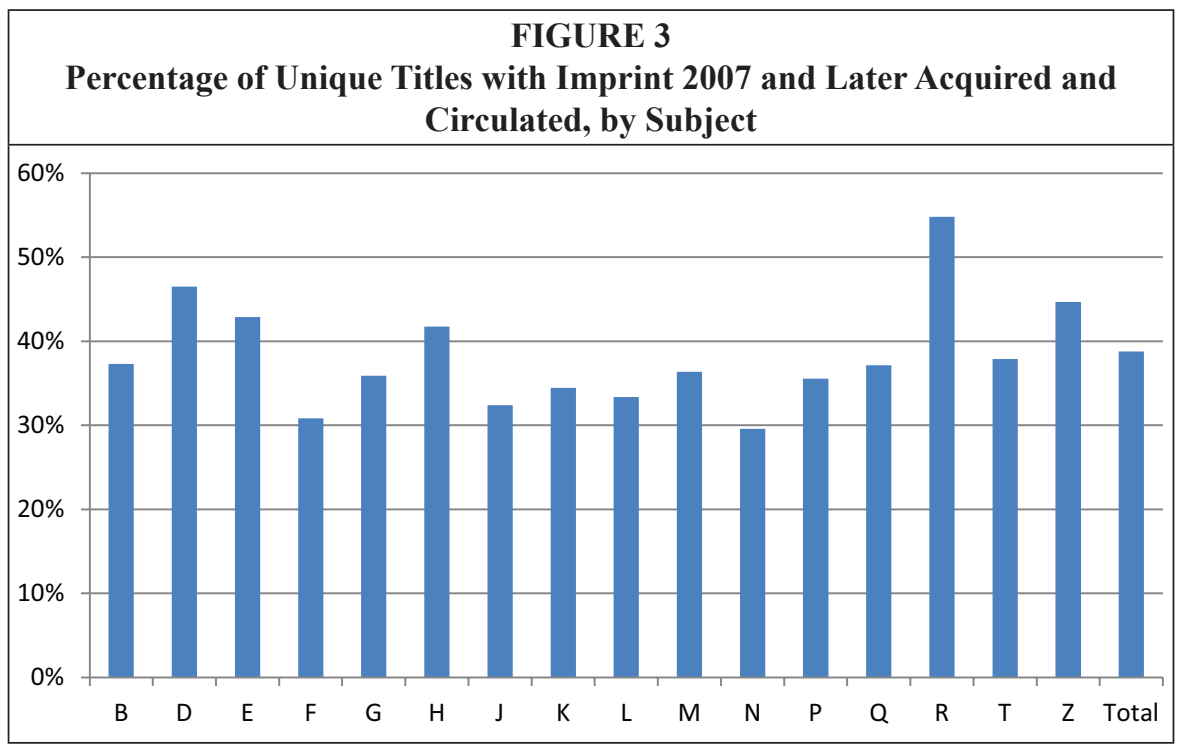


presented are based on circulation of titles acquired over the four-year period, it could be argued that our purchases have done even better since the more recent acquisitions had not had sufficient time to be used.

Examining ILL data and reverting to percentages of the whole data set, figure 4 shows the percentage of our unique title ILL borrowing by LC class. The largest proportion of borrowing was found in LC class $\mathrm{P}$, which accounted for nearly a quarter of the total ILL unique titles (24\%) for TCNJ Library users. This was followed by relatively high levels of borrowing in LC classes B (15\%) and H (14\%). Figure 5 further compares the
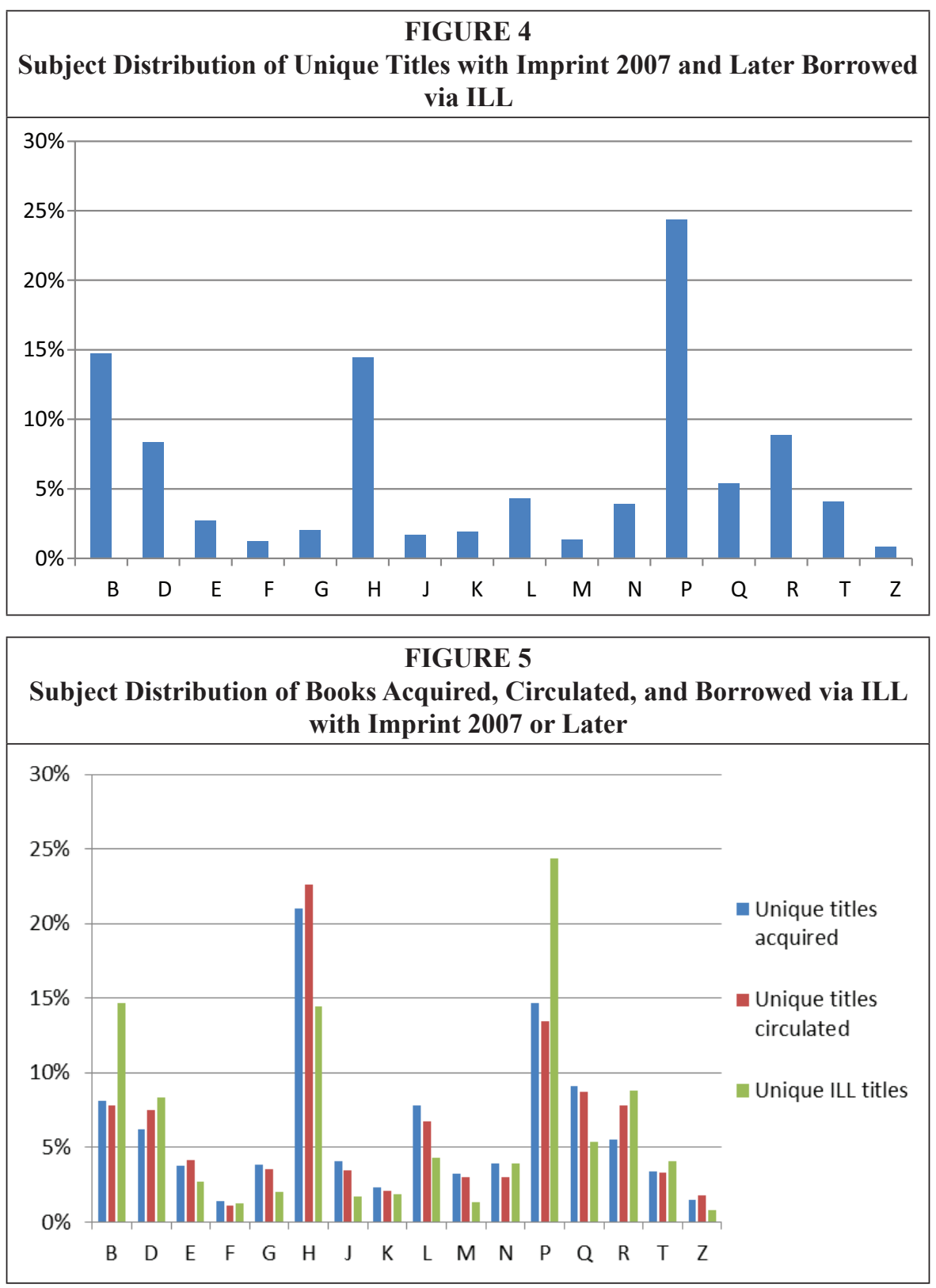
subject distribution of unique title ILL borrowing to circulation and recent acquisitions. Here we found that, while circulation of owned materials, as shown above in figure 2, roughly followed our acquisitions in most subject areas, ILL borrowing in LC classes B, $\mathrm{H}$, and $\mathrm{P}$ showed significant divergences from the subject distributions of circulation and acquisitions for the same LC classes. On the one hand, the subject distribution of ILL borrowing was almost twice as high in LC classes B and P as those of our acquisitions or circulation $(\mathrm{B}-15 \%$ in ILL versus $8 \%$ each in acquisitions and circulation, $\mathrm{P}-24 \%$ in ILL versus $15 \%$ in acquisitions and $13 \%$ in circulation). By contrast, it was significantly lower in LC class H (14\% in ILL versus $21 \%$ in acquisitions and $24 \%$ in circulation). These results could raise the possibility that we have been buying titles in LC class $H$ very well, or even disproportionately well-with our users in effect relying less on ILL borrowing in this subject area - and, conversely, that we have not been buying enough in LC classes B and P, thus making our users turn to ILL borrowing more often in these subjects.

Returning to the initial assumption that user borrowing (whether in the form of circulation of owned material or via ILL) is a metric for user need, we turned our attention to look more closely at how our total user borrowing broke down proportionately by subject to see where ILL was most heavily supplementing our collection. We developed the simple formula:

$\frac{\text { ILL }}{\text { (Circulation+ILL) }}=$ ratio of user needs not met by collection

By applying this formula to our data, we arrived at the result shown in figure 6, which shows the percentage of lending that was effected during the study period via ILL within each LC class as based on total circulation counts and unique title circulation counts. Thus, we see that over 25 percent of all of our total lending transactions from LC class B did not come from our collection, but via ILL. Likewise, nearly one-quarter of our total lending in LC class P was via ILL while ILL accounted for only 9 percent of total title lending in LC class $\mathrm{H}$. In all, nearly 15 percent of our total lending transactions were via ILL. When duplicate title lending is eliminated, an even more striking picture emerges, indicating that more than 35 percent of unique title lending in LC class B and nearly that much in class P was done via ILL. In toto, more than 20 percent of the unique

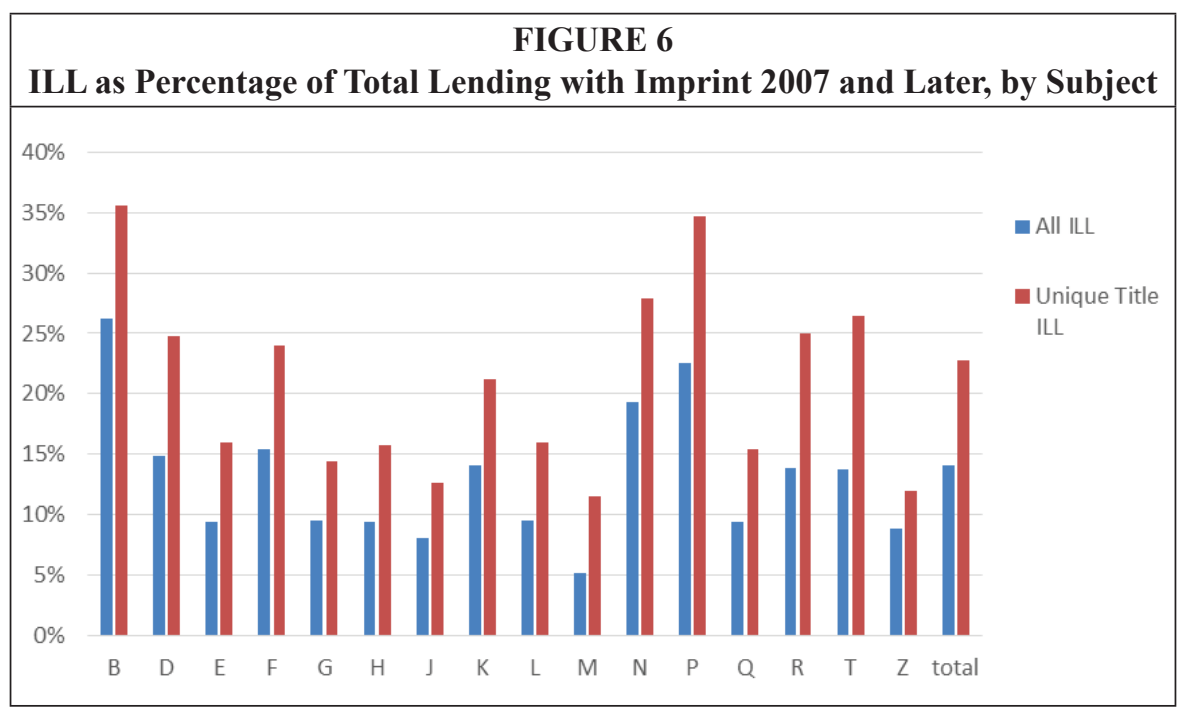




\begin{tabular}{|l|c|c|}
\hline \multicolumn{3}{|c|}{ TABLE 3 } \\
Unique Title Circulation \& ILL Transactions by Borrower Type, Post-2007 \\
Imprints
\end{tabular}

book titles in the study group delivered to our patrons did not come from our own collection, but through ILL. However, ILL accounted for only 16 percent of total unique title lending in LC class $\mathrm{H}$-less than half the percentage of ILL unique title borrowing in LC classes B and P. These results suggest, once again, that it may be advisable for our library to consider increasing our local collection development activities in LC classes $\mathrm{B}$ and $\mathrm{P}$ to better support the existing user needs for materials in these disciplines and reduce our reliance on ILL.

Because our Voyager ILS enables us to collect and assemble data on borrower types, applying these data to our analysis also provides another important way to examine collection use. Some interesting results are summarized in table 3, which breaks down unique title circulation and ILL data for 2007 imprints and later during the four-year study period by our main user groups (faculty, undergraduates, and graduate students). The table indicates that undergraduate students accounted for nearly 70 percent of local collection use (69\%), followed by faculty (25\%) and graduate students $(6 \%)$. On the other hand, undergraduates still account for a slight majority of ILL requests (53\%). Notably, however, the proportion of ILL requests from our faculty was much closer to that from our undergraduates at 43 percent, with graduate students following as a distant third (5\%). According to the latest institutional data available, the number of full-time undergraduate students, graduate students, and faculty at our college is $6,340,209$, and 349 , respectively. ${ }^{16}$ These data clearly suggest that faculty per capita turn to ILL far more heavily to meet their information needs. This result matches our

FIGURE 7

\section{Subject Distribution of Unique Titles Acquired and Circulated with Imprint 2007 and Later, by User Group}

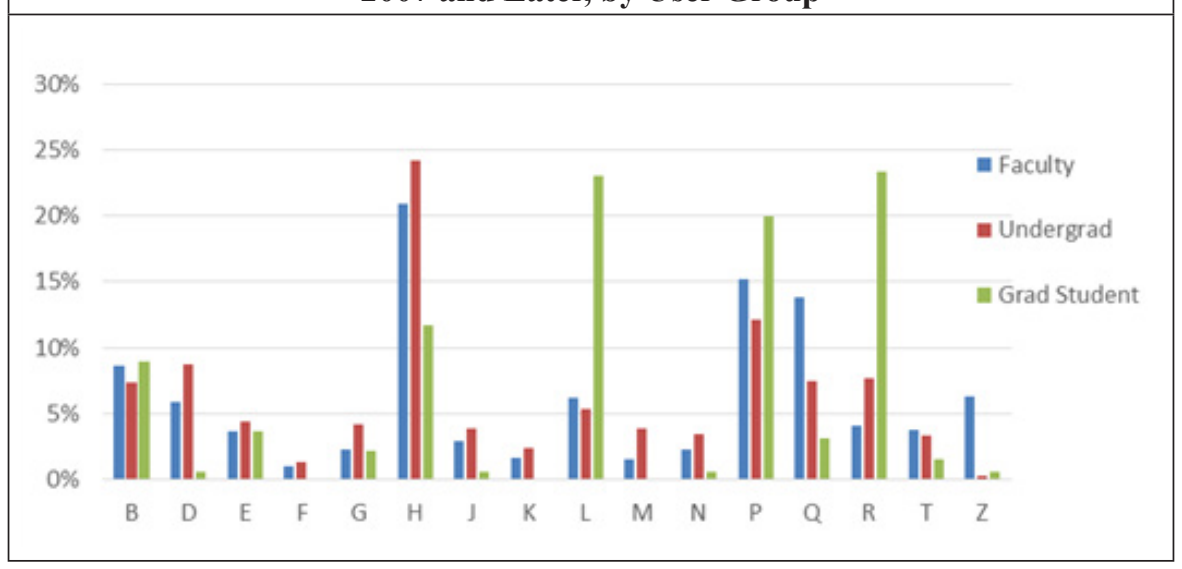


expectations, because our library collection is geared to current undergraduate research and study and serves the needs of the wider college community in a more limited way.

Turning our attention to a subject breakdown of circulation by user group (see figure 7), we find that the top three categories of our local collection used most heavily by undergraduates were in LC classes H (24\%), P (12\%), and D (World history and history outside the Americas-9\%). Our faculty borrowed most heavily in LC classes $\mathrm{H}$ and $\mathrm{P}(21 \%$ and $15 \%$, respectively). Unlike our undergraduates, however, they borrowed as heavily in LC class Q $(14 \%)$ as in LC class P. Graduate students borrowed most heavily in $\mathrm{R}$ and $\mathrm{L}$ at 23 percent, evidently reflecting the fact that our two main graduate programs are in nursing and education. Graduate students also borrowed almost as heavily in LC class P (20\%), a rate that was proportionally higher than for undergraduates and faculty apparently in large parts due to the fact, as shown in figure 8 , that there was less graduate borrowing in the other LC classes.

With regard to our ILL requests by user group and by subject, the results, as illustrated in figure 8 , show different borrowing patterns across the three groups. Undergraduates sought titles outside our local collection mostly in LC class P (21\%), with titles in LC classes $\mathrm{H}$ and B not far behind (16\% and $14 \%$, respectively). There were striking similarities in the top three ILL categories requested by our faculty, with titles in LC classes P, B, and H constituting well over half of the entire ILL requests $(27 \%$, $16 \%$, and $11 \%$, respectively). Different ILL borrowing patterns were found among our graduate students, with nearly 70 percent of their ILL requests concentrated in two LC classes: P (39\%) and R (29\%).

We were also interested in examining how the circulation of print titles in particular subject areas was distributed across different user groups. To that end, figure 9 illustrates the percentage of unique titles that were checked out by our main user groups-undergraduates, graduate students, and faculty-within each LC class. The proportion of study group titles from our collection that were borrowed by undergraduates collectively ranged from 55 percent in LC class L to nearly 90 percent in LC

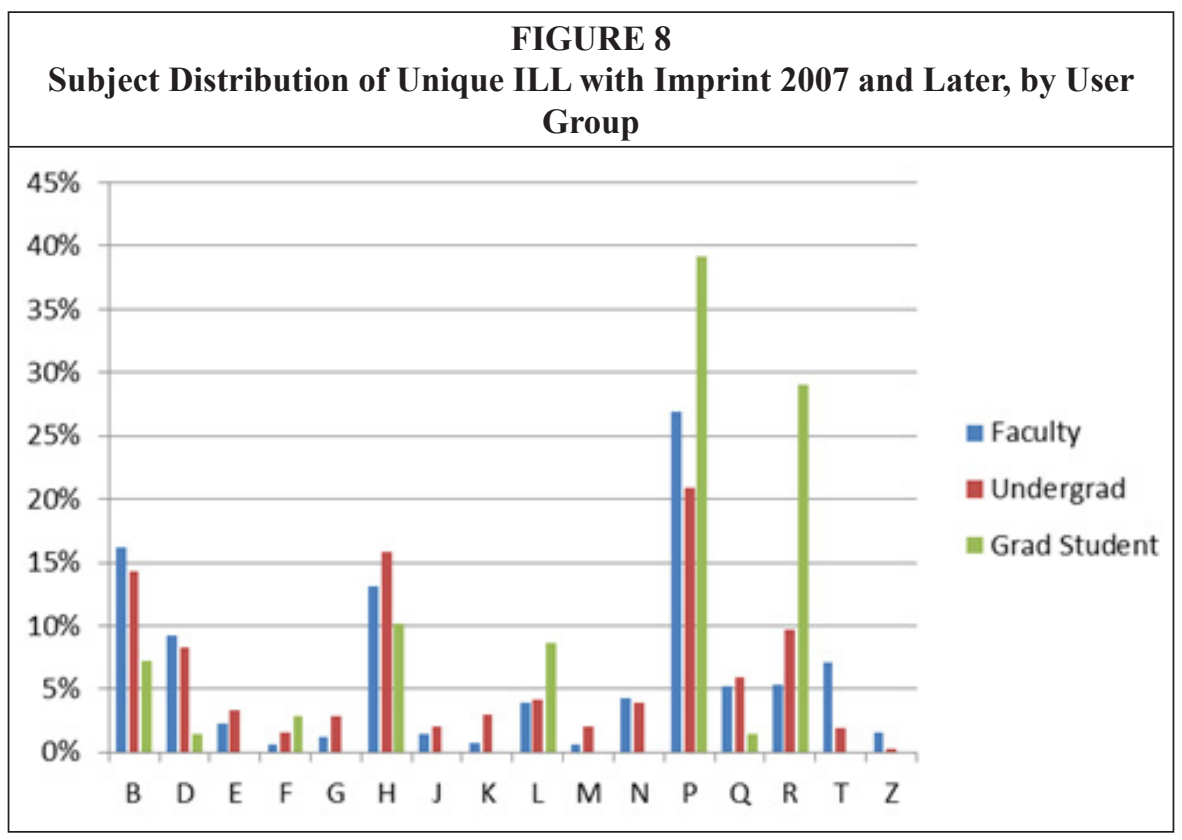




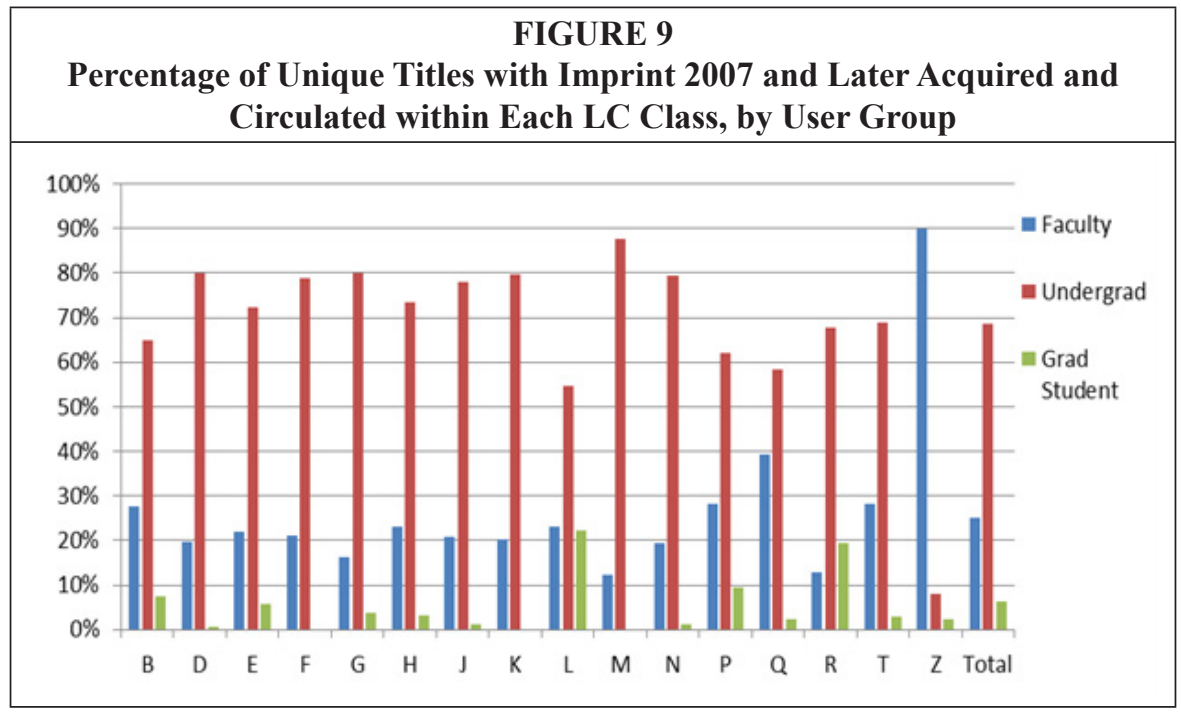

class M (Music). In fact, they were the heaviest users of our collection in all LC classes except $\mathrm{Z}$ (Library science and the like). We infer two things from this: First, there are simply many more undergraduates on our campus, as shown in table 3, so it is reasonable that this group accounts for more transactions. Second, the data might be seen as providing further evidence that our collection is meeting the needs of undergraduates better than it meets the needs of faculty or graduate students.

The above interpretation is evidently supported by a user-group analysis of the ILL borrowing data by LC class. Figure 10, also charted as a percentage of unique titles checked out by our three main user groups within each LC class, shows that ILL borrowing in most LC classes has been driven disproportionately by requests coming from our faculty. In the most extreme cases, we find that faculty accounted for

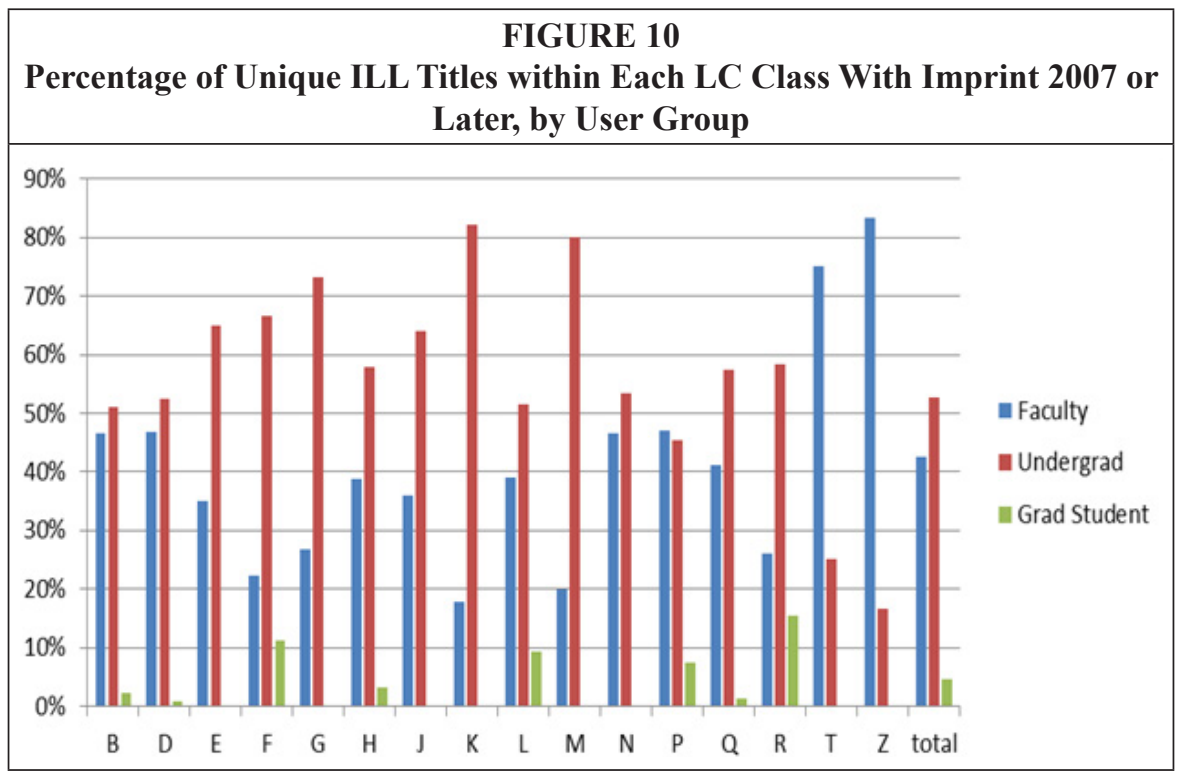


the overwhelming majority of unique ILL title requests in LC classes T (Technology) and $\mathrm{Z}(75 \%$ and $83 \%$, respectively). In many other LC classes, our faculty requests accounted for 40 percent or more of unique ILL borrowing. As shown in the same figure, there are some LC classes (for example, E and F [History of the Americas], G [Geography, anthropology, recreation]) in which nearly two-thirds or more of unique ILL borrowing was done by our undergraduate users. In fact, a large proportion of ILL borrowing in LC classes $\mathrm{K}(\mathrm{Law})$ and $\mathrm{M}$ was derived from undergraduate requests ( $82 \%$ and $80 \%$, respectively). Upon closer examination, however, we find that these ILL percentage disparities across LC classes may present a rather skewed picture of ILL data in our library, since those LC classes with the preponderance of undergraduate ILL borrowing in fact have registered few ILL requests overall (a total of 18 to 40 ILL unique titles borrowed over the four-year period). An analysis of the entire ILL borrowing data clearly confirms that faculty and graduate students, particularly when their smaller populations are factored into our analysis, were overall much heavier users of ILL on our campus.

\section{Discussion}

Taken together, a combined analysis of all the data points gathered over the four-year study period - acquisitions, circulation, and ILL - paints a picture of a mid-sized academic library whose local collection is doing well in meeting undergraduate needs but is less successful in meeting the needs of faculty researchers and graduate students. In turn, our faculty and graduate students apparently tend to find it necessary to compensate for the local collection shortfalls by reaching beyond the local walls and resorting much more frequently to ILL borrowing.

The study of our circulation transactions clearly reveals substantial use of the recent acquisitions of TCNJ library. We found that a consistent ratio of what we were circulating matched what we were acquiring. When the percentage of titles purchased and circulated is measured within the same subject areas, our library is doing especially well with nearly 40 percent of titles acquired having circulated at least once over the four-year study period between July 2008 and June 2012.

The analysis of our ILL borrowing data suggests the subject areas in which our users might find our collection adequate (that is, low ILL rate, as in LC class R), as well as those in which we have not been buying enough (in other words, high ILL requests, as in LC classes B, H, and P), which led our users to turn to ILL to fulfill the unmet needs. Using the formula "ratio of user needs not met by collection" developed for this study, we found that over 20 percent of the unique book titles delivered to our patrons came not from our own collection, but through ILL.

Our findings in circulation and ILL requests by patron group shed some light on how our library collection meets the needs of students and faculty respectively. The data show disparate patterns of user groups using library collection and ILL service. We learned, unsurprisingly, that both our undergraduate students and faculty borrowed more books in LC classes $\mathrm{H}$ and $\mathrm{P}$, which corresponds to the total borrowing data by subject. We also learned that graduate students borrowed most heavily in R (nursing) and L (education) reflecting our two main graduate programs. The ILL data also clearly suggest that faculty per capita used more of our ILL service to fulfill their information needs. This seems to validate our collection development policy, in that the library collection is developed to primarily support undergraduate education, followed by faculty research.

It cannot be emphasized too much, however, that the higher ILL usage among graduate students and faculty should not be read as an indicator of failures in our collection development since our collection policy is based on supporting undergraduate curricular needs. It could also be, of course, that undergraduates are less sophisticated 
library users than their senior scholars and thus do not pursue ILL as actively to obtain needed materials not available in the local library collection.

It is necessary to note that the results produced through our methods did not always lend themselves to a simple black-and-white interpretation. Our initial assumption in this study was that borrowing, whether from our collection or via ILL, was a viable metric for user need and that this need was of a fixed and consistent quality. That is, we assumed that all user needs were equal and that any need unmet by our collection indicated, by definition, a deficit in our collection policy that could, and should, be identified and remedied by modifications in the policy. A closer examination of our data on ILL requests, however, raised the possibility that user needs could not be measured in such a simple, linear fashion in the context of academic library collections. In reviewing the title lists of these requests, we noted outliers such as the disproportionate ILL interest in LC classes T and P. These we attributed to interest in books beyond our collecting scope, such as hobbyist titles and popular novels as well as to improved lending networks and better finding tools that have enhanced demand for titles that once might not have been readily discovered and requested via ILL. This finding suggests that identification of potential outliers for further investigation may be important in studies using similar methods and data sets. It also points to the desirability of running this study on a more granular level within LC classes, especially in broadly drawn classes such as B and P.

These caveats aside, while the results presented in this study may be specific to our library collections and user behavior, the methods used here should be equally valid and applicable to all types of libraries. These techniques allowed us to better understand what our acquisitions dollars are buying and how well our current acquisitions are meeting our user needs, offering us evidence-based information for future decisions about the strategic allocation of our collection development resources. Because the data-mining capabilities of current library systems allow us to easily compile different types of library use statistics, libraries may use the research methods presented here or further improve on them as needed to evaluate and enhance the effectiveness of their collection development practices.

\section{Conclusion}

The purpose of the research reported in this paper was to investigate quantitative methods of collection use analysis employing the types of library data that are extractable in the reporting modules of modern ILS and ILL systems. In particular, our study was significant in describing ways to connect circulation and ILL request data with acquisitions records to inform collection development practices and thereby better meet the changing needs of our patrons.

Locally, the study of our circulation and ILL transactions revealed how our library collection was meeting the needs of students and faculty in various subject areas. We noted overall a gratifying level of collection use as well as some met and unmet collection needs of TCNJ Library. We have shared our findings with the Collection Development Committee at TCNJ Library, and it is planned that future funding and selection decisions will incorporate this analysis on an ongoing basis. Of course, this analysis offers only a retrospective view of collection performance. Ongoing monitoring of patterns of purchasing and ILL requests will be needed as well, along with an awareness of shifting curricular needs.

We also learned that ILL transactions cannot always be viewed as deficits in our collection, concluding that, although ILL data reflect the unmet needs of library users, such needs should be monitored critically, since not all titles requested through ILL accord with the library's collection development policy. Indeed, all user need is not 
equal. As a result, ILL requests pose a question for selectors, not a formulaic answer. Instead of telling us what to buy (which would be the case with an automatic ILL purchase policy), we found that ILL requests might ask us if we should be buying specific titles or in specific subject areas.

During the study, we encountered several areas that warrant future research. Because the data-mining capabilities of the online systems allow us to compile usage and borrowing statistics, the current study focuses on monographs only. It would be interesting to devise a study on journal article usage where ILL counts might suggest changes in journal subscription practices. Investigating how e-book collection fulfills user needs based on usage by subject, patron group, and format preference will also be a desirable and valid research topic, as e-book collection has become increasingly popular in academic libraries. The study results should help libraries better develop their e-book collections.

Additionally, we would like to see a benchmark developed to assess collection use of both recent acquisitions and the entire collection. In particular, we would like to see what level of library collection use would be considered desirable and acceptable to justify that money is well spent. Also, as mentioned earlier, our study focused on materials purchased and used within the 2008-2012 fiscal years study period. Titles purchased in the latter parts of the study period did not have sufficient time for users to discover and use, likely resulting in low usage of those materials. A future study might be devised to measure collection use of all titles within a few years after they are purchased to provide a more objective and consistent measurement of material use. Likewise, a future study might measure collection use in terms of curriculum: for example, to analyze circulation and ILL data based on patron group and the schools they represent to learn their usage patterns and see if their needs are met.

We view the results of this study as a very successful attempt to methodically examine our collection use, to open better channels of communication between ILL and collection development, and to monitor our collection policies. What we sought to determine in this study was whether ILS data mining could produce useful information on user need that might be used prescriptively in collection development and whether some enumerative shorthand might be applied that would offer a direct feedback mechanism to our selectors. The methods used enabled us to provide a snapshot of how the print materials TCNJ Library has recently purchased are being used and where our different groups of users turn to ILL borrowing to meet their information needs unmet by our local collection. By correlating acquisitions and circulation data, we found that we could gauge and then appropriately communicate the success of our collection development practices in meeting user needs. We thus concluded that we could successfully continue to access and manipulate ILS data to form the basis for an ongoing analysis of circulation of library-owned titles that could offer valuable guidance to our selection policy. The wealth of results that can be gleaned from the variety and quantity of user data readily available from our local library systems demonstrates that the methods described in this study can yield valuable insights into user behavior patterns and that these methods can be easily adopted by other libraries whose ILS offers similar reporting capabilities.

\section{Notes}

1. Dennis P. Carrigan, “Toward a Theory of Collection Development," Library Acquisitions: Practice \& Theory 19, no. 1 (1995): 97-106.

2. Sonia Bodi and Katie Maier-O'Shea, "The Library of Babel: Making Sense of Collection Management in a Postmodern World," Journal of Academic Librarianship 31, no. 2 (2005): 143-50. 
3. A.K. Jain, "Sampling and Data Collection Methods for a Book-Use Study," Library Quarterly 39, no. 3 (1969): 245-52.

4. George S. Bonn, “Evaluation of the Collection," Library Trends 22 (1974): 265-304.

5. Debbi Dinkins, "Circulation as Assessment: Collection Development Policies Evaluated in Terms of Circulation at a Small Academic Library," College \& Research Libraries 64, no. 1 (2003): $46-53$.

6. Denise Brush, "Circulation Analysis of an Engineering Monograph Approval Plan," Collection Building 26, no. 2 (2007): 59-62.

7. Brian Adams and Bob Noel, "Circulation Statistics in the Evaluation of Collection Development," Collection Building 27, no. 2 (2008): 71-73.

8. Karen C. Kohn, "Usage-Based Collection Evaluation with a Curricular Focus," College \& Research Libraries 74, no. 1 (2013): 85-97.

9. Gary D. Byrd, D.A. Thomas, Katherine E. Hughes, "Collection Development Using Interlibrary Loan Borrowing and Acquisitions Statistics," Bulletin of the Medical Library Association 70, no. 1 (1982): 1-9.

10. Ibid., 8 .

11. William Anguilar, "The Application of Relative Use and Interlibrary Demand in Collection Development," Collection Management 8, no. 1 (1986): 15-24.

12. John N. Ochola, "Use of Circulation Statistics and Interlibrary Loan Data in Collection Management," Collection Management 27, no. 1 (2002): 1-13.

13. Jennifer E. Knievel, Heather Wicht, Lynn Silipigni Connaway, “Use of Circulation Statistics and Interlibrary Loan Data in Collection Management," College \& Research Libraries 67, no. 1 (2006): $35-49$.

14. The College of New Jersey, Center for Institutional Effectiveness, Facts and Institutional Figures, 2012-2013, available online at http://ir.pages.tcnj.edu/files/2013/08/Factbook_2012.pdf [accessed 11 February 2014].

15. See, for example, J. Parker Ladwig and Thurston D. Miller, "Are First-Circulation Patterns for Monographs in the Humanities Different from the Sciences?" Library Collections, Acquisitions, $\mathcal{E}$ Technical Services 37 no. 3/4 (2013): 77-84.

16. The College of New Jersey, Center for Institutional Effectiveness, Facts and Institutional Figures, 2012-2013. 